
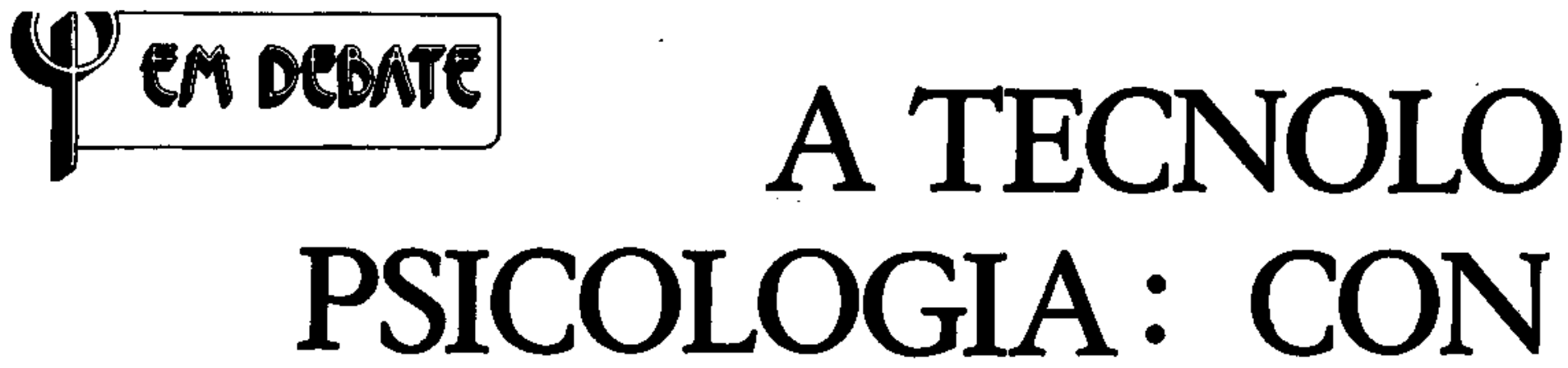

\author{
Três estudiosos apresentam a \\ Psicologia, Ciência e Profissão suas \\ posições a respeito da Psicologia Social \\ hoje, suas principais tendências, \\ possibilidades de atuação prática e \\ perspectivas futuras. Dentro disso, a \\ discussão de uma questão \\ controvertida: a Tecnologia Social.
}

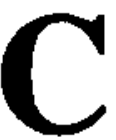
onjunto de conhecimentos aplicáveis na resolução de problemas enfrentados pelo homem em sociedade, a Tecnologia Social é definida e indicada, por alguns, como método para solucionar uma grande variedade de questöes, considerando-se a ideologia de seu aplicador um problema secundário. Para outros, nos moldes em que a Tecnologia Social vem sendo aplicada, a quiestão da ideologia se coloca como ponto fundamental de dis-

\title{
Ciência e tecnologia
serviço do homem
}

Psicología, Clência e Profissão: Quais as principais linhas da Psicologia Soctal hoje? Com qual delas seu trabalho se identifica?

Aroldo Rodrigues: Já houve tempo em que várias linhas transitavam na Psicologia Social com destaque mais ou menos igual. Recentemente, porém, 0 domínio do cognitivismo é indiscutível, o que justifica a seguinte afirmaçào de Markus e Zajonc (1985) no capítulo que escreveram para a recém-saída terceira edição do The Handboek of Social Psychology: "A Psicologia Social dos anos 50 e 60 era caracterizada por uma diversidade de enfoques. Algumas pesquisas eram apresentadas numa linguagem de estimulo-resposta, outras nas tradições da teoria de campo e da Gestalt e o restante era conceitualizado em termos cognitivos. A mudança desde então tem sido de proporções revolucionárias, impelindo praticamente todos os investigadores a verem os fenômenos psicossociais sob uma perspectiva cognitiva. Psicologia Social e Psicologia Social cognitiva são hoje quase sinônimos. $O$ enfoque cognitivo é agora claramente dominante entre os psicólogos sociais, não havendo, praticamente, competidores." De forma semelhante se expressa a psicóloga francesa Montmollin (1982) ao dizer: "por cognitivo devem ser entendidas, em psicologia social, as atividades psicológicas internas pelas quais o indivíduo (ou cada membro de um grupo) apreende e interpreta os estímulos sociais, pessoais, condutas e eventos observados, objetos e situaçōes sociais que se encontram em seu ambiente. Interessa-nos, pois, o que ocorre 'na cabeça do sujeito' quando se encontra na presença de outros, nos processos de aquisição, categorização, combinação, enfim, de processamento de Informaçōes, que termi- nam na expressāo verbal de um juízo de atribuição e/ou avalizaçăo." Eu, pessoalmente, me identifico inteiramente com esta linha cognitiva em Psicologia Social, embora muitas pessoas no Brasil (que obviamente nunca leram meus livros e artigos) me chamem de "behaviorista"...

PCP: Em que consistem as diferenças e semelhancas dessas linhas? $E$ como define e defende a sua posiçäo?

AR: A diferença entre a Psicologia Social cognitivista e a de características lewinianas e gestálticas não é muito grande; elas se distinguem porque esta última se prende a princípios rígidos da teoria de campo e da Gestalt, enquanto a Psicologia Social cognitiva contemporânea faz apelo às contribuiçöes de Lewin e da Gestalt sem se limitar a elas. $O$ enfoque cognitivo se distingue essencialmente do enfoque comportamentalista de vez que este quase não considera os processos me- 


\section{GIA}

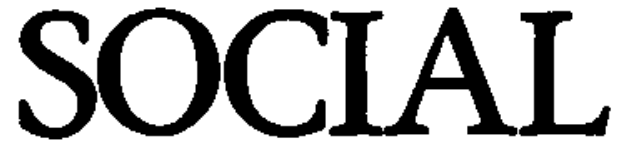

NA

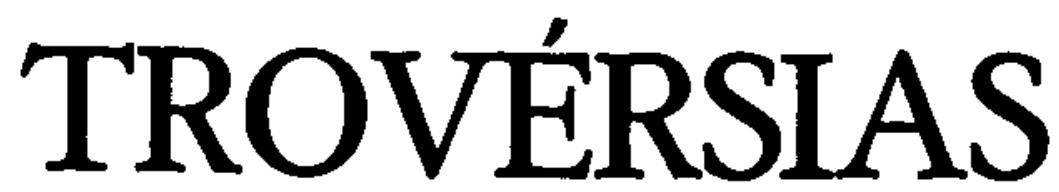

cussāo.

Psicologia, Ciência e Profissão convidou três psicólogos sociais para darem seus depoimentos sobre a questāo. Nossa idéia inicial era apresentar um texto coeso - resumo de um debate envolvendo os três entrevistados. Mas, na impossibilidade de reuni-los (pois não estavam, geograficamente, próximos) optamos por depoimentos individuais. A seguir, as opiniōes de Aroldo Rodrigues, coordenador do Programa de pós-gradu- ação da Universidade, Gama Filho, Ph. D.em Psicologia pela Universidade da Califórnia e introdutor das idéias de Jacobo Varela - especialista no assunto - no Brasil; Sílvia Lane, vicereitora acadêmica e professora titular de Psicologia Social no curso de pós- graduação da PUC - Pontifícia Uni versidade Católica e Wanderley Co do, professor de Psicologia Social na USP de Ribeirāo Preto e autor de "O que é Alienação"e "O que é corpolatria" entre outros títulos.

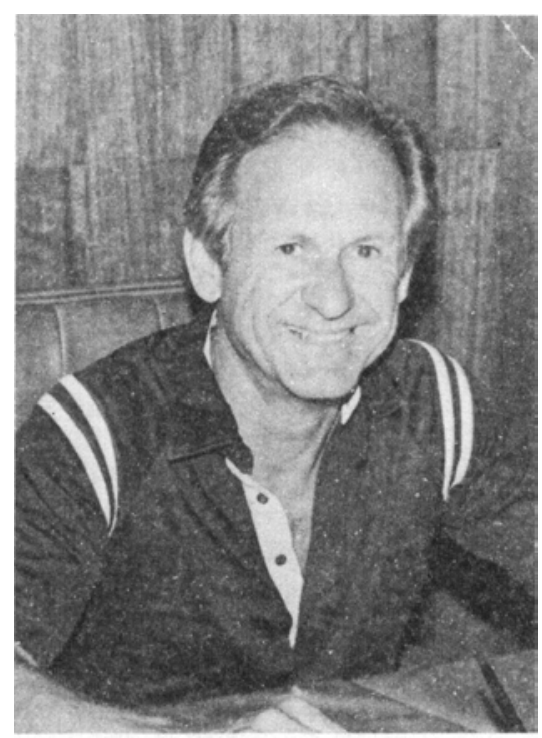

Aroldo Rodrigues

diadores não observáveis, porém claramente inferíveis, que caracterizam as cognições ou representrisojos sociais das pessoas.

PCP: Em que consiste a Tecnologia Social? Qual a sua relevância?

AR: A Tecnologia Social consiste na utilização dos achados científicos das Ciências Sociais a fim de resolver problemas sociais. $O$ tecnólogo social se fundamenta nos dados científicos existentes, combina-os e, através de sua criatividade, utiliza-os na resolução de problemas sociais. Como bem diz Jacobo Varela, o inventor da Tecnologia Social, "tecnologia é síntese, enquanto ciência é análise". Jacobo Varela, no Uruguai, e Euclides Sanchez e Esther Wiesenfeld, na Venezuela, são em minha opinião os mais destacados tecnólogos sociais da atualidade. A tecnologia social surgiu na América Latina e nāo nos países do primeiro mundo, provavelmente devido à necessidade premente de resolver graves problemas sociais existentes nos países do terceiro mundo. Os países desenvolvidos podem dar-se ao luxo de descobrir muitas coisas e não aplicá-las; hāo é o caso dos países do terceiro mundo, onde a gravidade dos problemas sociais está a exigir o esforço dos cientistas e dos tecnólogos sociais; os primeiros através de descobertas de relaçōes não-aleatórias entre variáveis, que permitem aos segundos criar soluçōes para a resolução de problemas concretos. Dedican. do-se à resolução dos problemas sociais, a relevância da Tecnologia Social dificilmente pode ser superestimada. É necessário que ela seja mais e mais desenvolvida entre nós; sem: pre, porém, ancorada em descobertas científicas sólidas, que facilitem o trabalho do tecnólogo social.
PCP:Quais as implicações éticas, políticas e ideológicas do uso da Psicologia Social?

AR: É claro que toda atividade prática envolve problemas de natureza ética, política e ideológica. A Tecnologia Social não está isenta desses problemas. É preciso que o tecnólogo social dejxe bem claro quais sāo os seus valores, para que as pessoas que com ele lidam possam julgar as soluçōes que apresenta. O trabalho do tecnólogo social há de ser franco, aberto, sincero e honesto. Isso se consegue através da explicitaçăo de seus valores às pessoas a quem sua atuação possa vir a influenciar. Não há como evitar a influência dos valores pessoais em sua atuação.

PCP: Qual o papel da Psicologia Social nesse quadro?

AR: A Psicologia Social, como ciência básica que é, tem muito a contribuir para a atividade do tecnólogo social. Embora a quase totalidade das pessoas discordem de mim, eu pessoalmente estou seguro de que a ciência é neutra em sua procura das relaçōes não-aleatórias entre variáveis. Admito que a escolha do tema e até o relatório do cientista possam não ser neutros. O produto final, isto é, o conhecimento novo que surge, este é inexoravelmente neutro, pois toda a comunidade cientifica o fiscaliza. Ninguém acredita ingenuamente no que um cientista diz; é necessário que ele prove o que diz. Na publicidade e na necessidade de o cientista descrever em detalhes como chegou ao conhecimento por ele apresentado é que reside a grande salvaguarda da ciência contra tendenciosidade e vieses pessoais. Penso, pois, que assim devem marchar a Psicologia Social e a Tecnologia Social: a primeira procurando séria, honesta e objetivamete, o conhecimento da realidade social em que vivemos; a segunda, baseada nesse conhecimento, planejando intervenções dedicadas à resoluçăo de problemas sociais.

PCP: Como está a Psicologia Social no Brasil e o que tem surgido de novo? AR: A Psicologia Social no Brasil não 